\title{
Subclinical rheumatic heart disease: A single center experience
}

\author{
Seyma Kayali, ${ }^{1}$ (i) Nuran Belder ${ }^{2}$ \\ ${ }^{1}$ Department of Pediatric Cardiology, Kecioren Training and Research Hospital, Ankara, Turkey \\ ${ }^{2}$ Department of Pediatrics, Kecioren Training and Research Hospital, Ankara, Turkey
}

\begin{abstract}
OBJECTIVE: Rheumatic heart disease (RHD) is still a major cause of morbidity and mortality in developing countries. The aim of the present study was to investigate asymptomatic RHD cases diagnosed by echocardiography without any acute rheumatic fever (ARF) history and to present the follow-up results.

METHODS: Children who had been admitted to the pediatric cardiology department between 2011 and 2017 for various reasons (e.g., sport participation and palpitation) and diagnosed with RHD by echocardiography without a history of ARF were included the study. Echocardiographic findings of the patients were evaluated retrospectively.

RESULTS: A total of 75 (55 girls and 20 boys) patients were included in the study. The median age of the cases was 13.6 (minimum 5 and maximum 18) years. The median follow-up period was 19.2 months, whereas the longest follow-up period was 66 months. At the time of admission, pathological valvular insufficiency was present only in the mitral valve in $69(89.3 \%)$ cases, only in the aortic valve in $2(2.7 \%)$ cases, and in both aortic and mitral valve in $6(8 \%)$ cases. Of the cases, $40(60 \%)$ were diagnosed as borderline RHD at the time of admission, and 30 (40\%) as definite RHD according to the World Heart Federation criteria. Of these cases, $88 \%$ remained the same as borderline RHD, and the findings of two patients improved from definite to borderline RHD. RHD of four patients deteriorated from borderline to definite RHD, and in two patients, valvular insufficiency completely resolved during the follow-up period. None of the cases needed valvular replacement.
\end{abstract}

CONCLUSION: RHD is still a serious health problem in Turkey. The sensitivity of echocardiography in detecting subclinical mild or asymptomatic cases is well known. For this reason, although it is not yet applied as a routine study, it is important to start the nationwide echocardiographic screening program.

Keywords: Asymptomatic; children; echocardiography; Rheumatic heart disease.

Cite this article as: Kayali S, Belder N. Subclinical rheumatic heart disease: A single center experience. North Clin Istanb 2018;5(4):329-333.

A cute rheumatic fever (ARF) is an important public health problem in developing countries including Turkey [1-3]. Although ARF and rheumatic heart disease (RHD) are considered to be parts of the same whole, their evaluation per se provides benefit. Indeed, in some patients with ARF, cardiac involvement is not seen at all, and in the medical history of nearly $50 \%$ of cases with RHD, diagnosis of ARF is not encountered because of the silent progression of ARF or unmade diagnosis. This condition is termed as subclinical carditis and is considered to be the major finding in both low- and moderateand high-risk populations according to the Jones criteria, which were lastly readjusted in 2015 [4].
Diagnosis of cases with definite ARF story bearing morphological and functional features of rheumatic heart disease (RHD) is easy to make. In certain cases with a definite history of ARF, having any valvular structural/ functional impairment is RHD unless proven otherwise [5]. However, the subclinical course leads to delayed diagnosis and onset of secondary prophylaxis at baseline, resulting in increased morbidity and mortality due to RHD.

Echocardiography is the most appropriate tool for the early diagnosis of subclinical RHD. In recent years, echocardiographic screening programs have been implemented in some countries in light of an increasing number of studies [6-8]. A guide was issued by the World

Received: September 15, 2017 Accepted: December 04, 2017 Online: August 13, 2018

Correspondence: Dr. Seyma KAYALI. Saglik Bilimleri Universitesi, Kecioren Egitim ve Arastirma Hastanesi, Cocuk Kardiyolojisi, Ankara, Turkey.

Tel: +90 3123569000 e-mail: ak-seyma@hotmail.com

(c) Copyright 2018 by Istanbul Provincial Directorate of Health - Available online at www.northclinist.com 
TABLE 1. The World Heart Federation echocardiographic diagnostic criteria of RHD for patients aged $\leq 20$ years

Morphological changes

Thickening of the anterior mitral valve leaflet ( $\geq 3 \mathrm{~mm}$, age-specific)

Thickening of the chordae tendineae

Reduced leaflet mobility

Extensive mobility of the leaflet tip during systole

Aortic valve RHD
Irregular or focal consolidation

Coaptation defect

Reduced leaflet mobility

Prolapse
Pathological valvular insufficiency

It should be observed in two different views

Insufficiency jet length should be $\geq 2 \mathrm{~cm}$ in at least one view The velocity in one complete envelope should be $\geq 3 \mathrm{~m} / \mathrm{s}$ Insufficiency jet should be pansystolic in at least one envelope It should be observed in two different views Insufficiency jet length should be $\geq 1 \mathrm{~cm}$ in at least one view Velocity should be $\geq 3 \mathrm{~m} / \mathrm{s}$ in early diastole Insufficiency jet should be pandiastolic in at least one envelope

Definite RHD (A, B, C, or D)
A. Pathological MR and presence of at least two morphological features of RHD of the mitral valve
B. Mitral stenosis (mean pressure gradient $\geq 4 \mathrm{mmHg}$ )
C. Pathological AI, and presence of at least two morphological features of RHD of the aortic valve
D. Concomitant presence of borderline rheumatic involvement of both mitral and aortic valves

Borderline RHD (A, B or C)

A. Presence of at least two morphological features of rheumatic involvement of the mitral valve without pathological MS or MR

B. Pathological MR

C. Pathological AI

AI: Aortic insufficiency; MR: Mitral regurgitation; MS: Mitral stenosis.

Heart Federation (WHF) for the rapid identification of RHD in patients without ARF to be used in these screening programs [9]. Table 1 summarizes the criteria found in this guideline.

Knowing the diagnostic criteria for RHD is also very important in terms of our country. However, there is no new study to determine the prevalence of RHD in our country, and also a national echocardiographic screening program is not available.

The aim of the present study was to analyze echocardiographically detected cases with RHD without ARF in light of the current diagnostic criteria of RHD and to share the follow-up results of these cases.

\section{MATERIALS AND METHODS}

Established cases with available echocardiographic evidence of pathological valve insufficiency under our surveillance without any history of ARF who were referred to the pediatric cardiology polyclinic between 2011 and 2017 with different clinical indications (e.g., participa- tion in sport activities and palpitation) were included in the study. All patients underwent transthoracic echocardiography using a Vivid 3 Expert (General Electric Medical Systems, USA) device with 3 and $7 \mathrm{MHz}$ probes by an experienced pediatric cardiologist. Mitral valve insufficiency jet was assessed throughout the systole in the apical four-chamber examination, and aortic valve insufficiency jet was assessed in the apical five-chamber examination throughout the diastole.

For the echocardiographic diagnosis of pathological valve insufficiency, the criteria previously defined and then updated by the WHF in 2012 were used [9]. According to the criteria, for mitral valve insufficiency, the following should be present: insufficiency jet should be seen at least two different sections, jet length should be at least $2 \mathrm{~cm}$, and peak flow rate should be at least $3 \mathrm{~m} / \mathrm{s}$ during systole. However, the criteria for aortic valve insufficiency were as follows: insufficiency jet should be seen at least two different sections, jet length should be at least $1 \mathrm{~cm}$, and peak flow velocity along the diastole should be $>3 \mathrm{~m} / \mathrm{s}$.

The presence of borderline and definite RHD was also 


\begin{tabular}{|c|c|}
\hline Age $($ mean $\pm S D)$ & $13.6 \pm 3.3$ years \\
\hline Gender, \% (female/male) & $73.3 / 26.7$ \\
\hline BMI $\left(\mathrm{kg} / \mathrm{m}^{2}\right)$ & $19.4 \pm 3.6$ \\
\hline \multicolumn{2}{|l|}{ Complaints (\%) } \\
\hline Chest pain & 36 \\
\hline Palpitation & 10.7 \\
\hline Murmur & 9.3 \\
\hline Syncope & 6.7 \\
\hline Other & 37.3 \\
\hline Murmur, \% (yes/no) & $26.7 / 73.3$ \\
\hline
\end{tabular}

SD: Standard deviation; BMI: Body mass index.

assessed according to the criteria including morphological valvular changes as determined by the WHF. The presence of mitral stenosis or at least two of the RHD morphological criteria in addition to pathological mitral regurgitation (MR) for the mitral valve was assessed to be sufficient for the definitive diagnosis of rheumatic mitral valve disease. For aortic valve insufficiency, the presence of at least two morphological criteria in the setting of pathological aortic regurgitation (AR) was assessed to be sufficient for the definitive diagnosis of rheumatic AR (Table 1).

Data were analyzed using the SPSS 22.0 statistical package program (SPSS Inc, Chicago, IL, USA). The distribution pattern of the data was evaluated by the Shapiro-Wilk test. Qualitative variables were expressed as numbers and percentages. Quantitative variables were expressed as mean \pm standard deviation for normally distributed data. Descriptive analysis was performed for the clinical findings of the patients, such as age, gender, and clinical features.

\section{RESULTS}

During a 6-year period, RHD was diagnosed echocardiographically in a total of 75 patients who were referred to us for different clinical indications. In only $26.7 \%$ of the cases, physical examination detected heart murmurs. It was determined that the patients were mostly girls, and that the most frequent cause of referrals was chest pain. Clinical and demographic characteristics of the patients are given in Table 2.

Echocardiographically, mostly pathological isolated MR was detected in patients $(89.3 \%)$. In any one of the
TABLE 3. Characteristic features of valvular involvement $(n=75)$

\begin{tabular}{lcc} 
& $\mathrm{n}$ & $\%$ \\
\hline $\begin{array}{l}\text { Valvular involvement } \\
\quad \text { Isolated MR }\end{array}$ & 67 & 89.3 \\
$\quad$ Isolated AI & 2 & 2.7 \\
$\quad$ MR+AI & 6 & 8 \\
Degree of valvular involvement & & \\
$\quad$ Mild & 65 & 86.7 \\
$\quad$ Moderate & 10 & 13.3 \\
$\quad$ Severe & 0 & 0 \\
Types of RHD & & \\
$\quad$ Borderline & & \\
$\quad$ Definite & 45 & 60 \\
\hline
\end{tabular}

AI: Aortic insufficiency; MR: Mitral regurgitation.

patients, severe valve insufficiency was not observed. The characteristics of valvular deficiencies in patients are given in Table 3.

However, morphological changes accompanying pathological valvular insufficiencies were detected in 30 (40\%) patients and diagnosed with definite RHD, while $45(60 \%)$ patients were diagnosed with borderline RHD. There was no difference between the age of diagnosis between patients with definite and borderline RHD.

Penicillin prophylaxis was initiated for all patients who met the criteria for borderline or definitive echocardiographic diagnosis. While 44 of the 75 patients were followed up for $>1$ year, the median follow-up period was determined as 19.7 months. At the end of the follow-up period, echocardiographic improvement was not observed in the majority of the patients, and valvular insufficiency of two cases regressed completely. The findings of valve insufficiency of the patients after the followup period are given in Table 4.

At the end of the follow-up period, $88 \%$ of the cases remained as borderline RHD at baseline, whereas findings of two cases regressed from definite RHD to borderline RHD, four cases with borderline RHD progressed to definite RHD, and two cases were completely normalized. When the patients progressed to definite RHD were examined, it was determined that the shortest and the longest follow-up periods were 6 and 66 months, respectively. In three of these patients, mitral valve thickening and prolapse of the anterior leaflet were detected by 
TABLE 4. Follow-up outcomes of the patients

\begin{tabular}{lcc} 
& $\mathrm{n}$ & $\%$ \\
\hline Follow-up period (months) & \multicolumn{2}{c}{$19.2 \pm 19.7$} \\
Disappearance of valvular insufficiency & 2 & 2.7 \\
Improvement in valvular insufficiency & 13 & 17.3 \\
Worsening of valvular insufficiency & 1 & 1.3 \\
Unchanged valvular status & 59 & 78.7 \\
\hline
\end{tabular}

Expressed as mean $\pm \mathrm{SD}$.

echocardiography, and pathological aortic insufficiency developed in one patient without prior relevant evidence. None of the patients developed valvular stenosis during follow-up. No patient needed replacement of the valve.

\section{DISCUSSION}

RHD is a major health problem in developing countries and is one of the leading causes of acquired heart disease worldwide $[6,10]$. Early recognition of the disease is important because it is known that secondary prophylaxis with penicillin prevents the progression of RHD. In recent years, with the frequent use of echocardiography, diagnosis of subclinical cases and early detection of the disease have been made possible, emphasizing the fact that the frequency of RHD is much more higher than previously thought $[8,11]$.

It is known that echocardiography is more sensitive than physical examination in detecting mild or asymptomatic RHD [7]. For this reason, the WHF has developed echocardiographic screening programs specifically for use in endemic areas and recently published in 2012 consensus guidelines that allow the standardized definitions of RHD as "definite" or "borderline" in diagnostic echocardiography [9]. These guidelines include Doppler evaluation of mitral and aortic regurgitation along with morphological features that can be caused by RHD in the mitral and aortic valves (Table 1 ).

The echocardiographic findings of cases with asymptomatic and non-ARF, whose information could be accessed during the 6-year period in our study, were evaluated in accordance with the current criteria of the WHF. To our knowledge, the present study is the first study performed in our country that evaluated asymptomatic cases in the pediatric age group according to the current diagnostic criteria of the WHF.

The most common isolated mitral valve involvement is RHD, but isolated aortic valve involvement can be seen in approximately $3 \%-5 \%$ of the patients $[12,13]$. In our study, mitral valve was also mostly affected in 75 (89.5\%) subclinical cases with RHD consistent with the literature. Isolated aortic valve involvement alone was found in $2.7 \%$ of the cases.

Although there are no clear echocardiographic criteria for mitral valve prolapse (MVP) in children as in adults, MVP associated with pathological mitral valve insufficiency seen in RHD is well defined in various studies such as valve thickening,excessive movement at the leaflet tip, and restricted leaflet movement $[14,15]$. Thus, it has been emphasized in children that irregular focal thickening of the mitral valve, especially the excessive mobility of the anterior leaflet in systole and its prolapse together with the eccentric insufficiency jet accompanying the restricted mobility of the posterior leaflet, should be evaluated in favor of rheumatic etiology [15].

In our study, valvular prolapse accompanied by pathological mitral valve insufficiency was evaluated as rheumatic MVP, and these cases were accepted as definite RHD. According to this, 26 (34.6\%) patients were diagnosed with baseline echocardiography, and 3 (4\%) patients with rheumatic MVP were detected by followup echocardiography.

Although the persistence of valvular insufficiencies in subclinical carditis is often reported in various studies, the natural course of this condition is not yet known [12, 16]. In the RHEUMATIC study, one of the largest case series, 6270 children aged 5-15 years were screened, and subclinical RHD was found during echocardiographic examinations; in 128 patients (especially girls in families with low socioeconomic status) and $4 \%$ of these patients, the disease progressed within 3-27 months [17].

Similarly, in a different study by Figureo et al,, patients were followed up for 5 years, valvular findings remained the same in $60 \%$ of the patients with subclinical carditis [18]. In our study, valvular insufficiency remained the same in $78.7 \%$ of the cases, $2.7 \%$ the patients were completely healed and in only one patient valvular insufficiency worsened. Taking into consideration the existing studies, conduction of a study with large case series with long-term follow-up results is needed so as to be able knowledgeable about the natural course of the disease.

Nevertheless, the pediatric age group gains the most benefit from the secondary protection after early diagno- 
sis of RHD, but typical valve pathologies may not be established due to their young age. For this reason, the definition of "borderline RHD" has been introduced with the current WHF diagnostic criteria, with the aim of increasing the diagnostic sensitivity especially in patients aged $\leq 20$ years. Since our present study includes only pediatric cases, we advocate regular follow-up at certain intervals in cases of borderline RHD in childhood, especially in endemic regions, such as our country, and emphasize the necessity of launching nationwide screening programs for the early detection of these cases.

Secondary prevention is absolutely necessary when diagnosing "subclinical definite RHD" using echocardiography. However, it is recommended in patients with borderline RHD in areas where the prevalence of RHD is too high with inadequate access to valve surgery [19]. In our study, secondary prophylaxis with penicillin was initiated in all cases with definite RHD and in patients diagnosed as borderline RHD due to the higher prevalence of RHD in our country, and recurrent episodes of ARF were not observed in any case during follow-up.

Limitations of our study include the lack of a screening study, the limited number of patients, and the inadequate length of the follow-up period.

As a result, RHD is a health problem that still retains seriousness in our country. The sensitivity of echocardiography in the detection of subclinical, mild, or asymptomatic cases is well known. Detection and follow-up of subclinical cases with RHD owing to the development of echocardiographic screening programs especially in an endemic region similar to our country are necessary to overcome this relevant lack of information. For this reason, although not a routine approach yet, it is important to launch nationwide echocardiographic screening programs.

\section{Conflict of Interest: The authors declare no conflict of interest.}

Financial Disclosure: The authors declared that this study has received no financial support.

Authorship Contributions: Concept - S.K., N.B.; Design - S.K., N.B.; Supervision - S.K., N.B.; Materials - S.K., N.B.; Data collection \&/or processing - S.K., N.B.; Analysis and/or interpretation - S.K., N.B.; Writing - S.K., N.B.; Critical review - S.K., N.B.

\section{REFERENCES}

1. Akalın F. Novelties in acute rheumatic fever. Turk Arch Ped 2007;42:85-93.

2. Ozer S, Hallioğlu O, Ozkutlu S, Celiker A, Alehan D, Karagöz T. Childhood acute rheumatic fever in Ankara, Turkey. Turk J Pediatr 2005;47:120-4.

3. Marijon E, Mirabel M, Celermajer DS, Jouven X. Rheumatic heart dis- ease. Lancet 2012;379:953-64. [CrossRef]

4. Gewitz MH, Baltimore RS, Tani LY, Sable CA, Shulman ST, Carapetis J, et al.; American Heart Association Committee on Rheumatic Fever, Endocarditis, and Kawasaki Disease of the Council on Cardiovascular Disease in the Young. Revision of the Jones Criteria for the diagnosis of acute rheumatic fever in the era of Doppler echocardiography: a scientific statement from the American Heart Association. Circulation 2015;131:1806-18. [CrossRef]

5. Eroğlu AG. Update on diagnosis of acute rheumatic fever: 2015 Jones criteria. Turk Pediatri Ars 2016;51:1-7. [CrossRef]

6. Marijon E, Celermajer DS, Tafflet M, El-Haou S, Jani DN, Ferreira $\mathrm{B}$, et al. Rheumatic heart disease screening by echocardiography: the inadequacy of World Health Organization criteria for optimizing the diagnosis of subclinical disease. Circulation 2009;120:663-8. [CrossRef]

7. Mirabel M, Bacquelin R, Tafflet M, Robillard C, Huon B, Corsenac $\mathrm{P}$, et al. Screening for rheumatic heart disease: evaluation of a focused cardiac ultrasound approach. Circ Cardiovasc Imaging 2015;8:pii:e002324. [CrossRef]

8. Roberts K, Cannon J, Atkinson D, Brown A, Maguire G, Remenyi B, et al. Echocardiographic Screening for Rheumatic Heart Disease in Indigenous Australian Children: A Cost-Utility Analysis. J Am Heart Assoc 2017;6:pii:e004515. [CrossRef]

9. Reményi B, Wilson N, Steer A, Ferreira B, Kado J, Kumar K, et al. World Heart Federation criteria for echocardiographic diagnosis of rheumatic heart disease -an evidence-based guideline. Nat Rev Cardiol 2012;9:297-309. [CrossRef]

10. Remenyi B, Carapetis J, Wyber R, Taubert K, Mayosi BM; World Heart Federation. Position statement of the World Heart Federation on the prevention and control of rheumatic heart disease. Nat Rev Cardiol 2013;10:284-92. [CrossRef]

11. Saxena A. Increasing detection of rheumatic heart disease with echocardiography. Expert Rev Med Devices 2014;11:491-7. [CrossRef]

12. Caldas AM, Terreri MT, Moises VA, Silva CM, Len CA, Carvalho AC, et al. What is the true frequency of carditis in acute rheumatic fever? A prospective clinical and Doppler blind study of 56 children with up to 60 months of follow-up evaluation. Pediatr Cardiol 2008;29:1048-53.

13. Roodpeyma S, Kamali Z, Zare R. Rheumatic fever: the relationship between clinical manifestations and laboratory tests. J Paediatr Child Health 2005;4197-100. [CrossRef]

14. Marcus RH, Sareli P, Pocock WA, Barlow JB. The spectrum of severe rheumatic mitral valve disease in a developing country. Correlations among clinical presentation, surgical pathologic findings, and hemodynamic sequelae. Ann Intern Med 1994;120:177-83. [CrossRef]

15. Atalay S, Uçar T, Ozçelik N, Ekici F, Tutar E. Echocardiographic evaluation of mitral valve in patients with pure rheumatic mitral regurgitation. Turk J Pediatr 2007;49:148-53.

16. Tubridy-Clark M, Carapetis JR. Subclinical carditis in rheumatic fever: a systematic review. Int J Cardiol 2007;119:54-8. [CrossRef]

17. Saxena A, Ramakrishnan S, Roy A, Seth S, Krishnan A, Misra P, et al. Prevalence and outcome of subclinical rheumatic heart disease in India: the RHEUMATIC (Rheumatic Heart Echo Utilisation and Monitoring Actuarial Trends in Indian Children) study. Heart 2011;97:201822. [CrossRef]

18. Figueroa FE, Fernández MS, Valdés P, Wilson C, Lanas F, Carrión F, et al. Prospective comparison of clinical and echocardiographic diagnosis of rheumatic carditis: long term follow up of patients with subclinical disease. Heart 2001;85:407-10. [CrossRef]

19. Çağlı K, Gölbaşı Z. How to diagnose rheumatic heart disease with echocardiography? Turk Kardiyol Dern Ars 2016;44:440-4. 